УAK 332.1

ББК 65.04

DOI 10.22394/1682-2358-2020-5-40-48

V.I. Malyy, Doctor of Sciences (Sociology), Professor, Head of the Corporate Economy Department, Povolzbsky Institute of Management named after P.A. Stolypin, Branch of the Russian Presidential Academy of National Economy and Public Administration

V.V. Gusev, Candidate of Sciences (Economics), Docent of the Corporate Economy Department, Povolzhsky Institute of Management named after P.A. Stolypin, Branch of the Russian Presidential Academy of National Economy and Public Administration

\section{RUSSIAN INNOVATION MONOTOWNS: POSITIVE EXPERIENCE IN SOCIO-ECONOMIC DEVELOPMENT}

The role of Russian single-industry entities (towns), where innovative products important to the economy are produced, is studied. It is stated that positive situation in such single-industry formations depends to a large extent on regional and local public authorities initiative, as well as the preparedness of the core enterprises management. Positive experience of monotowns development in some regions of the Russian Federation is considered.

Key words and word-combinations: monotown, innovation, engineering, demography, development project.
B.И. Мальй, доктор сочиологиеских наук, профессор, заведуюший кафедрой корпоративной экономики Поволжского института управления имени П.А. Стольтина - филиала Российской академии народного хозяйства и государственной службь при Президенте РФ (email:sreda@email.ru)

B.В. ГусеВ, кандидат экономических наук, дочент кафедрь корпоративной экономики Поволжского института управления имени П.А. Стольтина - филиала Российской академии народного хозяйства и государственной службь при Президенте РФ

(email: vladgus2006@yandex.ru)

\section{РОССИЙСКИЕ \\ ИННОВАЦИОННЫЕ МОНОГОРОАА: \\ ПОАОЖКИТЕАЬНЫЙ ОПЫТ \\ СОЦИААЬНО- ЭКОНОМИЧЕСКОГО РАЗВИТИЯ}

Аннотаџия. Исследуется роль российских монопрофильных образований (моногородов), в которых осуществляется инновационное производство важных для экономики хозяйства видов продукции. Утверждается, что положительная ситуация в подобных монопрофильных образованиях зависит во многом от инициативности региональных и местных органов государственной власти, от подготовленности руководства градообразующих предприятий. Рассматривается положительный опыт развития моногородов в отдельных регионах Российской Федерации.

Ключевые слова и словосочетания: моногород, инновации, машиностроение, демография, проект развития. 
M особое территориальное поселение, в котором сощиально-экономическая ситуаџия зависит от уровня экономического развития, финансового благополучия и сощиальной деятельности Аоминирующего в городе градообразующего предприятия. Соответственно, если градообразующее предприятие в моногороде приходит в упадок (причины подобного явления - кризис, технологическая отсталость, финансовая несостоятельность, отсутствие спроса, неконкурентоспособность продукции, недостаток инвестиций, сырьевых и трудовых ресурсов и т.п.), население моногорода также начинает испытывать экономические и социальные проблемы, а сам населенный пункт становится территорией нестабицьности, «болевой точкой» экономики и соџиальной жизни. В то же время в российских моногородах часто производится уникамьная продукция, не имеющая аналогов, необходимая народному хозяйству и значимая с точки зрения национацьной экономической безопасности.

Монопрофимьные поселения начали формироваться еще в царской России, во времена освоения периферийных территорий и существования крепостного права, когда в проџессе освоения отдаленных районов, богатых полезными ископаемыми, появился феномен «город-ЗавоА»; при этом на основателя промышиенного производства трудицись не крепостные крестьяне, а крепостные рабочие, приписанные к преАприятию. В качестве примера можно привести освоение Ураца, современных Пермского края и Свердмовской области купцами Строгановыми и Аемидовыми, где в результате их Аеятельности были заложены основы российской тяжелой промышиенности и оружейного дема [1]. Заводы и рабочие поселки вокруг них получици статус города только в советский период, а до этого у них не бымо даже собственных названий - например, поселок Кушва на Урале до революции назывался Кушвинский завод, Невьянск - Невьянский завод, Сысерть - Сысертский завод и т.А. [2, с. 232].

Подиинный расџвет монопрофильных поселений пришелся на советскую эпоху. В результате проведения советским государством патерналистской соџиальной политики моногорода превращались в источники соџиального благополучия, промышиенное производство позволяло получать населению высокую по советским меркам заработную пиату, эффективное функционирование крупных предприятий способствовало подлержканию социальной инфраструктуры в полностью работоспособном состоянии (например, организация соџиальной жкизни и снабжения в моногороде Тоцьятти во времена СССР). ОАнако в условиях скачкообразного перехода к рыночным отношениям, общей политики деиндустриализации в 1990-е годы, упаАка отраслей промышиенности, прежде всего машиностроения, моногорода превратицись 
в сложное наследие плановой системы. Из них начал наблюдаться исход жителей, социальная и инженерная инфраструктура городских поселений пришиа в упадок. Пиановый характер советской экономики и разбросанность населения по территории страны в соответствии с могикой расположения производительных сил, исход населения периферийных моногородов, переезд граждан в более благополучные регионы и места проживания приводят к «социальному опустыниванию» территории регионов, к конџентрации населения в крупных городах и вокруг них, в так называемых «агломерациях». Политика создания агломераций, проводимая сегодня в Российской Федераџии, на наш взгляА, недальновидна в плане стратегического удержания территории страны. Потенциально монопрофильные поселения могли бы стать точками роста новой экономики, сосредоточением высоких технологий, промышиенного производства, которое в случае динамичного развития способно переломить кризисные тенденџии на положительные, создать в экономике определенный инновационный задем. ОАнако подобный подход к развитию моногородов сопряжен с соблюдением органами власти и бизнесом целого ряда внешних и внутренних условий, которые заслуживают подробного рассмотрения.

На наш взгляА, существуют определенные признаки именно инновационных моногородов, которые позволяют выделить их из всей совокупности монопрофильных образований. Прежде всего это инноваџионный потенциал градообразуюшего предприятия как перспективная способность за счет имеющихся технологий производить важную, востребованную государством и обществом продукцию, готовность к внеАрению карАинальных инноваций. Инновационный потенциал следует напрямую связывать с инвестиционным потенциалом, так как охотнее всего государственные и частные инвестиџии пойдут туда, где производимый градообразующими преАприятиями продукт имеет ощутимый государственный заказ или хорошие рыночные перспективы.

Соответственно, градообразующие преАприятия и поселения в целом могут иметь смедующие оџенки инвестиџионного и инноваџионного потенциала:

1) предприятия с высоким потенциалом;

2) преАприятия со среАним потенциалом;

3) предприятия с низким инвестиционным и инноваџионным потенциалом.

Вторым критерием, который характеризует инновационность развития моногорода, явцяется нацичие в нем молодежи, имеющей перспективы Аля профессионального развития. Чтобы моногород не вымирал, в нем должны проходить активные демографические процессы: превышение рождаемости над смертностью, высокий прирост рожАаемости. В контексте развития перспектив Амя молодежки особое значение приобретает достойная заработная плата в моногороде. 
На основании данного критерия моногорода можно классифицировать слеАующим образом:

1) с большим количеством молодежки и расширенным воспроизводством населения, в том числе, трудовых ресурсов (сушественное превышение рождаемости наА смертностью);

2) с недостаточным количеством молодежки и простым воспроизводством трудовых ресурсов (когда рождающиеся примерно в том же количестве заменяют умерших);

3) вымирающие моногорода с высокой убылью и устойчивым исходом населения, прежде всего студентов, учащихся, молодых кадров.

Третий критерий - наличие развитой сферы образования, широкого научно-образовательного пространства. Научно-образовательная сфера в моногородах в советское время была во многом «заточена» под специализацию монопрофильного поселения. Например, в сырьевых, добывающих моногородах были сосредоточены филиалы профильных вузов и техникумов; в энергетических моногородах - филиалы энергетических вузов и т.А. Если на градообразуюшем предприятии требовался специалист узкой, специфической профессиональной направленности, например, в атомной отрасли или гиАроэнергетике, предприятие по направлению обеспечивало конкретному мицу учебу в соответствующем вузе с условием Аальнейшего возвращения и работы в родном городе. В настоящее время в связи с тенденџиями урбанизации и развития агломераџий данный критерий уходит в прошлое, но фактически, чтобы удержать молодежь в моногороде, необходимо качественное высшее и среднее профессиональное образование, а затем - достойная заработная плата при работе на предприятиях моногорода.

В соответствии с этим критерием российские моногорода можно поАразделить на посемения:

1) с развитой сферой образования;

2) со сферой образования среднего уровня;

3) с деградирующей сферой образования, закрытием вузов, училиш и комледжей, исходом научно-педагогических работников, объединением (укрупнением) школ с одновременной миквидацией неперспективных образовательных учреждений.

Четвертый критерий связан с оџенкой моногорода по категории «производство». Несмотря на дискуссии о постиндустриальном обществе, цифровой экономике, компьютерных технологиях и Аругих реалиях современной жизни, отметим, что приоритет в хозяйственной системе Ао сих пор принадлежит производственным отраслям, создающим реальный продукт и на этой основе - реальное (а не цифровое) национальное богатство. Цифровая экономика, на наш взгляА, призвана быть вспомогательным инструментом аля реального производства. Следовательно, само производство в настоящее время должно быть развитым, так как предприятие 
в состоянии кризиса сложно вновь перезапустить и при этом добиться высоких результатов.

По Аанному критерию можно выделить следующие уровни промышленного развития моногорода, отражающие условия его функционирования:

1) высокий уровень отражает наличие развитого промышиенного производства в моногороде и сбыт промышиенной продукции в Аругие регионы;

2) средний уровень отражает слабо развитую промышленность и сбыт промышиенной продукции только на мокальный рынок;

3) низкий уровень отражает отсутствие промышиенности в моногороде и закупки необходимой промышменной продукции, товаров народного потребления в Аругих регионах [3] .

Пятый критерий, на наш взгляА, заключается в следующем - кто является актором (субъектом) инновационного развития моногорода. Согласно этому критерию, такими акторами могут быть:

1) государственные органы федеральной и региональной власти;

2) муниципальные органы управления;

3) отечественный и иностранный бизнес.

В зависимости от того, кто будет субъектом инноваџионного развития моногорода, приобретают значение такие важные параметры экономической динамики, как комплексное территориальное планирование, объем инвестиций в производство и соџиальную сферу, привлечение в моногород молодых перспективных кадров, текущее и перспективное состояние соџиальной инфраструктуры и т.А. Безусловно, в ситуации с наличием сильной системы федеральной и региональной власти, скудостью местных бюджетов в связи с имеющимся налоговым законодательством и «непрозрачностью отечественного бизнеса приоритет в развитии инновационных моногородов должен принадлежать инвестиџиям первой группы.

Инновационный тип развития моногородов остро ставит проблему высшего и среднего образования; научно-образовательной среды как важнейшего компонента инновационного потенциала, формирование которого во многом зависит от усиций на региональном (местном) уровне от проводимой региональной (местной) инноваџионной политики. От уровня образования во многом зависит потенциал инновационной восприимчивости житемей к нововведениям, а также мотивационный настрой к технологическим новшествам, преобразующим структуру потребления и стиль поведения населения, его образ жкизни. Современный технологический укмад преАполагает органическое взаимопроникновение, интеграцию технологических и социальных инноваций, поэтому старение населения в провинции и его недостаточное инноваџионное сознание затрудняют внедрение нововведений. В России наблюдается традиционно высокий потенциал инженерной мысли и изобретательства, однако в на- 
стоящее время он, как и потенщиал науки, явцяется невостребованным. Рационализаторы и изобретатели должны попадать в соответствующую внешнюю инноваџионную среду, чтобы их предложения были востребованы. Без проведения соответствующей государственной политики и финансирования предлагаемых иниџиатив российским раџионализаторам и инноваторам невозможно воплотить в жизнь свои достижения.

На наш взгляд, большими потенциальными инновационными возможностями обладают монопрофильные поселения, в которых сосредоточены предприятия машиностроения, в том числе оборонные предприятия и преАприятия Авойного назначения. Советские технологии, развивавшиеся в механических производствах, машиностроении, приборостроении и обороннопромышленном комплексе, во многом опередили свое время. За истекшие годы экономического реформирования эти технологии не только морально и физически не устарели, но и подтвердили свою уникальность, поэтому справедливо утверждение, что машиностроительные моногорода явАяются средоточием отечественных инноваций. В связи с курсом Министерства обороны и MBА РФ на перевооружение российской армии и симовых структур моногорода, в которых сосредоточены оборонные предприятия, получили Аополнительный импульс, «второе Аыхание» в своем развитии, государственный заказ на производство новых видов вооружений и амуниции.

Предприятия гражданского машиностроения оказались в настоящее время в труаной ситуаџии потому, что в 1990-е годы был взят курс на деиндустриализацию страны, построение системы рыночных институтов, создание могистических цепочек в ущерб производству товаров категории «А» (среАств производства). Помимо этого, в 1990-е годы применялась стратегия закупки импортных промышяенного оборудования, станков, симовых и рабочих машин, промышиенной оснастки, несмотря на их высокую стоимость по сравнению с отечественными аналогами. В результате потенциал машиностроительных предприятий в моногородах в настоящее время ослаблен, наблюдаются недофинансированность, недостаток инвестиџий, ухудшение состояния инновационной базы. Острую и актуальную проблему функционирования отрасли машиностроения представляет каАровый вопрос, обусловленный старением трудовых колмективов и оттоком молодых каАров с предприятий.

ПреАставцяется, что Аля эффективного развития инноваџионных моногородов в Российской Федераџии необходимо принятие следующие мер:

1) максимальное сохранение потенщиала градообразующих предприятий и государственный заказ дмя них, в том числе за счет средств государственного бюджета, министерств и ведомств, крупных системообразующих компаний;

2) развитие в моногородах соџиальной и рыночной инфраструктуры (больниџ, поликлиник, Аворџов культуры, кружков Аля детей, развитой торговли, банковских структур, страховых компаний, активного жкицищного строительства); 
3) развитие системы образования, формирование обновленных взаимосвязей «градообразующее предприятие - вуз - техникум - профессиональное училище - средняя школа», работа со школьниками в пиане профориентации, направление на учебу молодых кадров по требуемым спещиальностям за счет предприятий, привлечение молодежи на предприятие на места с Аостойной заработной платой.

Необходимо также отметить, что в тех регионах, где органы власти занимают активную созидательную позицию по отношению в повсеАневной жизни провинции, где налажены и развиваются деловые контакты межАу градообразующими преАприятиями, властью и муниципацитетами, ситуация в моногородах намного благополучнее, чем там, где подобного контакта нет. В подтверждение можно привести опыт респубцик Татарстан и Башкортостан, где Ааже в провинциальных населенных пунктах работают промышленные предприятия, при которых полноџенно функџионируют средние и высшие учебные заведения. Так, на территории Республики Башкортостан находятся девять моногородов. В 42 км от Уфы в моногороде Благовешенск, получившего свой статус в 1941 г., сегодня проживают 35 тыс. человек. ЗАесь сохранен промышленный потенциал советского времени. Градообразующим предприятием является арматурный завод (БАЗ), на котором работают более двух тысяч человек; в городе функционируют еще шестнадцать производственных организаций, вкАючая судоремонтный завоА, мебельную фабрику, завоА ЖБК, преАприятие по производству одноразовой пластиковой посуды. Развита система образования: имеются семь средних общеобразовательных школ, многопрофильный профессионамьный комлеАж, Башкирский архитектурно-строительный коммеАж. Оттока населения из моногорода практически нет, молодежь уезжает за высшим образованием в Уфу, Казань и Аругие научные центры, но затем, как правимо, возвращается дмя работы на предприятиях города [4].

В Республике Татарстан - пять моногородов: Нижнекамск, Набережные Челны, Чистополь, Зеленодольск и Менделеевск. Показательной с точки зрения муниципального развития явмяется ситуация в Набережных Челнах, расположенном в 237 км от Казани, с населением 534 тыс. человек. За последние десять мет население моногорода увеличилось на 20 тыс. человек. Градообразующим предприятием является Камский автомобильный завод (КАMАЗ), на котором работают 52 тыс. человек. В городе также функционируют более тридцати крупных и средних промышленных преАприятий, включая ООО «Камский тракторный завоА», АО «Набережночелнинский крановый завоА», АО «СеАан» (производство автомобильных фильтров), АО «Генерирующая компания», АО «Камский метамлургический завоА». По сути моногороА преАставляет собой автомобильный кластер. В Набережных Челнах имеются 104 средние школы, двенадџать техникумов и комледжей, шесть головных вузов, десять филиалов вузов, пять театров, четыре кинотеатра, восемь музеев, шесть дворцов кумьтуры 
и концертных залов. Молодежь уезжает за получением образования в Москву, Казань, Уфу, Самару и другие научные центры, но впоследствии чаше всего возвращается амя работы на преАприятиях моногорода [5] .

В Челябинской области - шесть моногородов, в том числе знаменитый город уральских оружейников ЗАатоуст. Его население - 165 тыс. человек. В моногороде - семь машиностроительных преАприятий, включая $\mathrm{AO}$ «ЗАатоустовский метаммургический завоА», АО «ЗАатоустовский машиностроительный завоА», АО «ЗАатоустовская оружейная фабрика», часовой завод, швейную фабрику. Система образования представлена 36 общеобразовательными школами, четырьмя техникумами, четырьмя филиалами екатеринбургских и челябинских вузов. Культурную сферу составляют Араматический театр, четыре музея, семь дворџов культуры и культурновыставочных центров, библиотека. Отмечено, что насемение моногорода ЗАатоуст незначительно убывает, но это является общим демографическим трендом на Урале и в Сибири; происходит это сравнительно медленными темпами, поэтому перелом негативных тенденций на положительные возможен в цюбой момент при обеспечении стабильного функционирования экономики и устойчивых перспектив Амя предприятий города [6].

ЗАатоуст вошем в число кучших проектов развития перспективных моногородов России, представленных в январе 2017 г. на Гайдаровском форуме в Москве. В настоящее время городской вмастью планируется, что АОля молодежки среди населения составит в перспективе не менее 30\%; а заработная плата будет выше средней по региону на 10\%. Фундаментальными направлениями развития ЗАатоуста определены производство оружия, метамургия, а также спорт и туризм - создание многофункџионамьного спортивного центра в горной местности Уреньга [7] .

Эффективное развитие инновационного моногорода предполагает структурное сочетание трех важнейших компонентов, акторов так называемой «тройной спирали»:

а) федеральных, региональных и местных органов государственной власти, которые развивают разАичные проекты в городской среде, устанавливают «правика игры» и предусматривают источники для финансирования деятельности;

б) учреждений высшего профессионального образования, которые занимаются научными исследованиями и вносят существенный вкмаА в экономику моногорода через малые инноваџионные предприятия;

в) бизнес-структур, которые создают инновационные организаџии совместно с учебными заведениями [8] .

ОАнако, на наш взгляА, это возможно мишь при проведении соответствующей государственной политики индустриализации экономики и возрождения инновационных отраслей промышленности. Сегодня эффективно

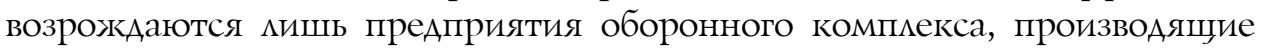
продукцию «Авойного назначения», а преАприятия машиностроения, про- 
изводство готовой гражАанской высокотехнологичной продукџии по-прежнему находятся в кризисе. На базе кризисных предприятий экономику современного инновационного моногорода построить весьма проблематично. Более того, как свидетельствует опыт моногорода Петровск Саратовской области, если высокотехнологичное предприятие останавливается по Аюбым причинам и при этом сохраняет свой производственный потенциал (территорию, станки и оборудование), запустить его потом все равно весьма сложно, так как происходит отток с предприятия квалифицированной рабочей силы, у оставшихся работников теряются трудовые навыки. Именно поэтому, несмотря на распоряжение Правительства РФ создать в Петровске «Территорию опережающего соџиально-экономического развития» [9], полноџенно запустить Аанный проект, «оживить» машиностроительные предприятия моногорода пока не удалось. Машиностроительные преАприятия - «Петровский эмектромеханический завоА «Молот» и АО «Завод автозапчастей АМО ЗИА» - по-прежнему не работают, инвестиции на них привлечь достаточно сложно.

В настояшее время в моногороде реализуются проекты преимушественно по благоустройству городской среды: приведение к современным стандартам городского парка, реконструкщия фонтана, установка аттракционов и детских площадок, создание модочной пристани [10]. ОАнако изначально цель создания ТОСЭР в Петровске заключалась прежде всего в возрождении деятельности машиностроительных заводов. Сможет $и и$ региональная и муниципальная власть Саратовской области решить задачу привлечения инвестиций и обновления деятельности градообразующих преАприятий в ТОСЭР «Петровск» - покажет ближайшее время.

\section{Библиографический список}

1. Сальников А. Строгановы - Демидовы: две стороны Урала. URL: http://pensionerrossii.ru/news/1150-stroganovy-demidovy-dve-storony-urala.html

2. Тургель И.Д. Монофункциональные города России: от выживания к устойчивому развитию. Екатеринбург, 2010.

3. Чалдаева Л.А., Скиданова Ю.В. Критериально-методический подход к классификации моногородов: теория и практика. URL: https://www.elibrary.ru/item.asp?id=25781899

4. Благовещенск (Башкортостан). URL: https://ru.wikipedia.org/wiki

5. Набережные Челны (Татарстан). URL: https://ru.wikipedia.org/wiki/

6. Златоуст. URL: https://ru.wikipedia.org/wiki/

7. Златоуст - город будущего! URL: https://zlatoust.tv/biblioteka/skolkovo.php

8. Ииковии Г. Модель Тройной спирали. URL: https://cyberleninka.ru/article/n/modeltroynoy-spirali/viewer

9. О создании территории опережающего социально-экономического развития «Петровск»: постановление Правительства РФ от 27 сент. 2017 г. № 1166. «// URL: http://static. government.ru/media/files/SXiOABlgFDRAZkh5bD0dcvOh52p9j2NB.pdf

10. В Петровске заканчивается второй этап реконструкции городского парка культуры и отдыха. URL: https://saratov.gov.ru/news/v_petrovske_zakanchivaetsya_vtoroy_etap_ rekonstruktsii_gorodskogo_parka_kultury_i_otdykha/ 